\title{
Discussion on Design and Functions
}

\author{
Yalike Bai \\ Jingdezhen University of Ceramics \\ Jingdezhen, China 333003
}

\begin{abstract}
The function not only refers to any sort of attribute that allows the product satisfied to the demand of the user, but it also an advantageous effect or potency wielded from the substance or the method. In this article, the relation of materialist dialectical philosophy lying between the design and the function was concluded through research approaches of documentation and logical reasoning; in addition, the structural law embedded inside the beauty of the function was also found by the method of qualitative analysis. This structural law and functional design theory attach a certain referential value in the researches of design theoretical system.
\end{abstract}

Keywords—design; products; function

\section{INTRODUCTION}

Design is an activity involving with creation, of which the core issue is attributed to the function and in turn the function will embody the nature of the design. Basically, the design and function consist of the highly unified product created by art and science, which is a unity not available for separation. A useful function is able to meet various needs of human; as the view of Bruce Kleston on the design, "It is designing that ties the applications in the product design of art and science once again. It can decipher our silent passion of satisfying the need. The products born in the new era is about to gratify our desire to the excitement, stimulation, and functionality. This is to say the product should be featured with interestingness, attractiveness and practicability." Hence, the function of usefulness is the one credited as the core of a design, and due to which the functional design will be attached with importance. In the aspect of functional design, the creations that the human beings constantly change the existing materials allowing them to change, gain benefit, renewal, and advance will endow the functions of a product with greater perfection, stability, reliability, humanization, and being better in line with the future orientation of sustainable development. And this is the core issue that we are required to solve in the future.

\section{THE RELATION BETWEEN DESIGNING AND FUNCTION}

Turning over the history of human design, we can find that the basic property of a product is the function; and the function refers to the driving force for people to design and yield products. The function is the existence value of the product, and the very fundamental attribute of the product existing as a useful object; the product with no efficacy is a waste, which is to say that the usefulness, also the function, occupies the first place. ${ }^{1}$ In the opinion of the author, the object of a designing is pointed to the product, while the goal of the designing is not the product itself but to meet various needs of people, that is the functional design, also known as the design for humans. Endowed with no function, the product itself loses the significance of the designing; only embedded with certain functions, the designing of a product can harvest the designing value.

Through the Marxist materialist dialectics, the relation between the design and function were studied, from which it can be find that the function of a product is the form of a substance and material, and acts on the human beings in order to exert its value. And the design is the effect or counteractive effect of the spiritual level on a substance and material, playing a guiding role in thoughts of creating a function and proposing solutions. Between designing and function, they are in a mutuality of coexistence and interactions and inter-transformation, see "Fig. 1" If we compare the relationship between designing and function to the one between the "soul" and "flesh", it is easy to understand that the relation tying these two is inseparable and is a philosophical relation of materialist dialectics on with they can coexist, interdepend with each other and develop together. Take an ordinary ceramic pot as the example; it is used to grow plants. The value of the ceramic pot itself is the function of use, and its designing goal is to gratify the demands of human beings for the edibility, ornamental nature, ornamentality, absorption of harmful gases, cleaning air, beautifying environments, and cultivating tastes. If the flowerpot is severely damaged and cannot be repaired, then the ceramic flowerpot loses the value of function in use, that is, it loses the purpose and significance of the design. Since that the loss of the function in use, for the ceramic flowerpot, is equivalent to the loss of its value of existence, that is, the loss of the very fundamental attribute of a product, due to which it turns to be waste. From the above example analysis, it can be determined that the design is the soul if the ceramic flowerpot is likened to the flesh. The body and soul shares such a relation which is inseparable and integrated. If one of them disappears, the other half will disappear. The crushing of ceramic pots by external forces means that its material basis no longer exists, that is, the design meaning of its design purpose disappears at the same time.

Li Yanzu, The beauty of creation [M], Beijing: China Renmin University Press, 2000:331. 
The purpose of a designer to design a product is basically to satisfy the people with various functions obtained by them when the people are using the product, which will become meaningful and earn values. The function is the first element of designing a product; the loss of the function will lead everything to being meaningless and worthless.

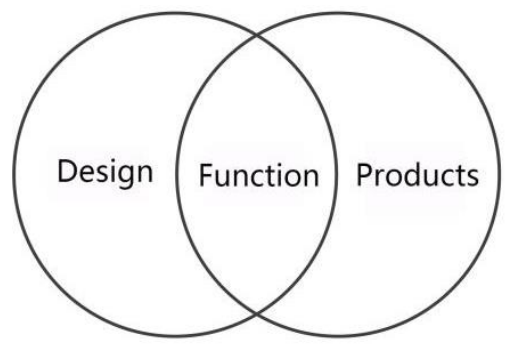

Fig. 1. The relation schema of design and function.

\section{FUNCTION AND BEAUTY}

The function of a product can be created in various forms among which the pure function in use and the function in artistic beauty are two closely linked elements of a product designing. In a product design, the function and beauty are linked together and the basic attributes natured in design. Therefore, we can categorize the function of designing products into two categories: the functional beauty of technical products and the functional beauty of artistic products. The beauty of the functionality of these two products is based on material materials and process technology to achieve the beauty of a function. Because they share certain internal links and functional attributes, some design products are difficult to classify or convert. For example, automobiles bring people convenience in life, and various operating devices generated in the use of automobiles give people automatic, simple, high-efficiency, and comfortable feelings, all of which are the spiritual experience. Its formation is related to the use of functions formed under the perfect technology. From the use of them, people perceive the unlimited functional beauty of the humanization design of the high-tech product. In addition to the beauty of the car's use of functions, there is also the aesthetic beauty of appearance and appearance. We can appreciate the fine art of flowing lines, bright and bright spray paint art, lighting, sound, and signs. A car is able to concurrently post the beauty of use and the beauty of viewing; thus, the author believes that the beauty of the function of some products is more complex. It can be technically beautiful and artistically beautiful, of which they can be equivalent or can convert the primary and secondary relationship, and even transform into the other beauty of functions, such as the multifunctional deformed furniture, smart phones, artificial intelligence robots, etc. Besides, ordinary products can also be converted to other products through recycling, and some products are composed of materials that can be formed from recycled functional materials. For example, glass containers, plastic industrial products, metal products, etc., many of their materials can be recycled and reused to produce other products. The products at this time have been transformed into the beauty of other functions, so science and technology also determine the means and basis of the beauty of a function.

The premise for the beauty of a function is that the product is designed and created based rational thoughts and materials. With various perfect functions of a product, people embrace the satisfaction, and harvest the feelings of beauty, thus rising to the spiritual realm which is both emotional and rational in "Fig. 2".

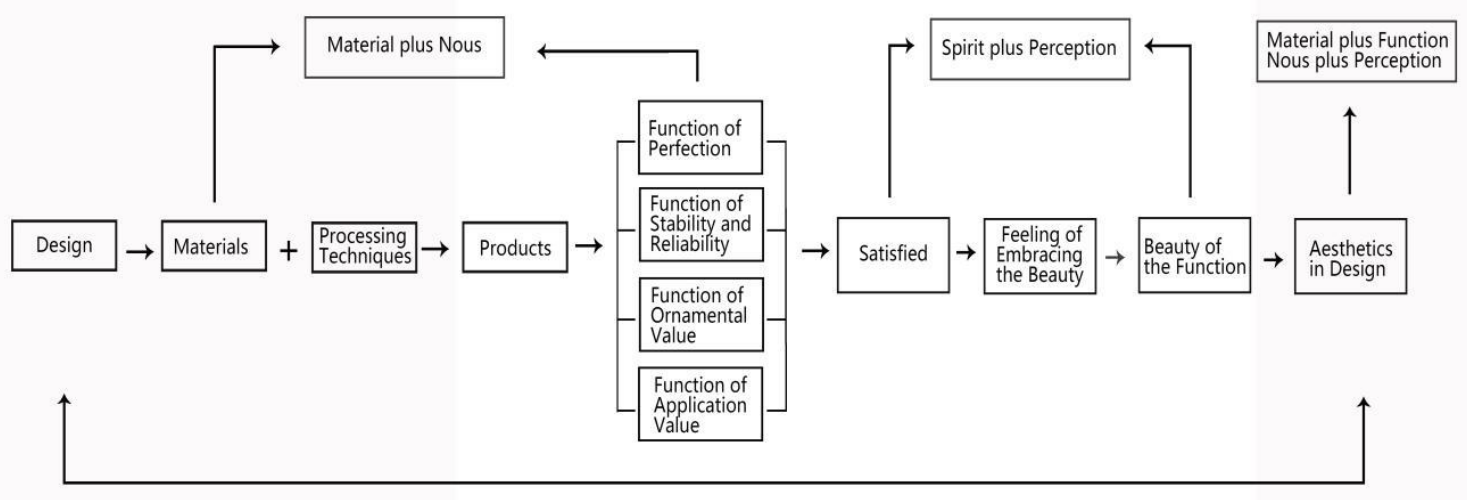

Fig. 2. The structural law inside the beauty of the function.

Considering the human as the starting point, the internal structure of the functional beauty is to research the dualnature of the nous and perception of human beings. The aim of the human creating objects is to give satisfaction to the diverse needs of humans; in turn, while people obtain the gratification from various functions of the products, they also embrace the satisfaction of nous and perception. Such a satisfaction itself is sort of complicated, which even might be the unity of two thoughts of the person. The author deemed that this unified thought will produce sublimation for the beauty as high as the spiritual realm of the mankind when it harvests the satisfaction. This sublimation of the spiritual beauty of the human can directly motivate the development of the aesthetics in design; eventually, the aesthetics in 
design will place counteract on the development of the design. These two parts are to operate, cycle and develop through the structural law of the beauty of a function.

From the above analysis of the internal structural laws of functional beauty, the conclusion that the beauty of a function is the core of design aesthetics is obtained, which can be confirmed from the history of the development of design aesthetics. Based on the view of the author, the forming history of design aesthetics has been being gradually established by the improvement of the function of design products. Humanity has experienced a long way in its understanding of the function of designing products and the beauty of their functions. Since the 18th century, the understanding of people to the beauty shares no correlation with the function, but has been shaped into a purely artrelated object. With the continuous emergence of Western industrial revolution and new ideas, which influenced the understanding of philosophers and estheticians to a certain extent, the view of aesthetics can be rationally coming forth from the German philosophical thoughts after Hegel. Thanks to the continuous improvement of science and technology from the end of the 19th century to the beginning of the 20th century, the products featured with both graceful appearance and useful functions could be manufactured in the machinery factories, at the same time people began to re-contemplate the relationship between the function and the beauty. Accordingly, has caused many scholars in Western countries to attach great importance to and put forward new aesthetic concepts such as "functional beauty" and "industrial beauty" before and after, which gradually formed the establishment of modern product aesthetic thought afterward. For example, at the end of the 19th century, the Chicago school architecture master Sullivan put forward the idea of "form obeying function", the concept of unity of technology and art of Bauhaus in the early 20th century, and the theory system of "internationalism" to improve the beauty of a function step by step. Worth of being noted here, the functionalist ideological trend that was formed at the beginning of the 21st century put forward the "functional decision-making form". They deemed that the thing was of beauty as long as it owned the usefulness. Functionalists have formed a design aesthetic viewpoint of "practical function is the first" and they have been paying attention to its importance all the time until now. From this point of view, the beauty of a function plays an important role in design aesthetics.

In short, the discovery and establishment of the internal structural law of the "beauty of function" can appropriately complement the theoretical system of the beauty of function, and thus to a certain extent verify the core theoretical position in design aesthetics.

\section{FUNCTION AND HUMAN}

In addition to the primary key elements of the design, the function must also be considered closely related to various disciplines such as materials, processes, technology, ergonomics, natural environment, and humanistic environment. Therefore, the function of the design is a complex design system in which multiple related disciplines intertwine and influence each other and develop together.
Although the function is the primary consideration in design, it does not exist alone. It is closely linked with the surrounding design-related systems. According to the opinion of the author, no matter how complicated and varied the design function is, it is designed for people and the ultimate goal is to be used by people and serve people. As described in the Introduction to Design edited by Liu Haiping, he stated that, "Design is a creative activity that humanity carries out for a specific purpose.... Any design, from as small as a needle to as big as a high-rise building, is the activity created by the rational thoughts and perceptions of humans to satisfy the demand of people in the process of production and living of human beings. Although the results of a design are embodied in the form of 'objects', the design activities are not directed at 'objects' but are ultimately directed at 'People' and pointed to 'things'."2 Since the design is designed for "people", the design function is also designed for people. In the Demand for Human Life composed by Maslow, an American psychologist, he made an explanation on the original impetus relationship between design and creation resulting from human needs. From the Theory of Man's Needs came up by Maslow, it can be analyzed that the various levels of the demand of people come from the needs of different social groups and different groups of people; moreover, the design of creation is to meet the different needs of different people. That is to say that the function of design is inseparable from human life, because people must live when they are alive. People need design-productfunction-expense-use-life-requirements for life needs, and the cycle of development and change is in an endless change. However, people in different time and space have different needs. Therefore, research on people is the ultimate goal of functional research in "Fig. 3". For example, the purpose of using oil lamps or candles for ancient people was to obtain lighting functions. However, the lives of people have changed nowadays. People use electricity to illuminate. The function of oil lamps or candles has been replaced by the function of modern lighting. According to market research, it was found that in the small-scale micro-environment of remote areas where oil lamps and candles are not energized, most of them are used in specific environments and even their functions have undergone essential changes. For instance, the candles in the restaurant are used to create a romantic atmosphere, and the lamps in the outdoor shop are used to create a wilderness atmosphere. This shows that the function of the product changes with time and space, and that one function is converted into another function. . Therefore, people of different time and space have different life needs, and different designs and different functions are produced under different life requirements.

The object of the function is used to be the people all the time. The basic characteristic of designing products is that science and art are highly integrated to serve people. The high unification of humans and objects fully reflects the person's superior wisdom and culture. Life indicates the direction and purpose of designing for the designers; as the change occurring in the life of people, the design functions

\footnotetext{
2 Liu Haiping, Introduction to design [M], Beijing: Peking
} University Press, 2010:76. 
of products also follow changes. And functions are continuously developed and changed for the needs of people under the complicated life environment.

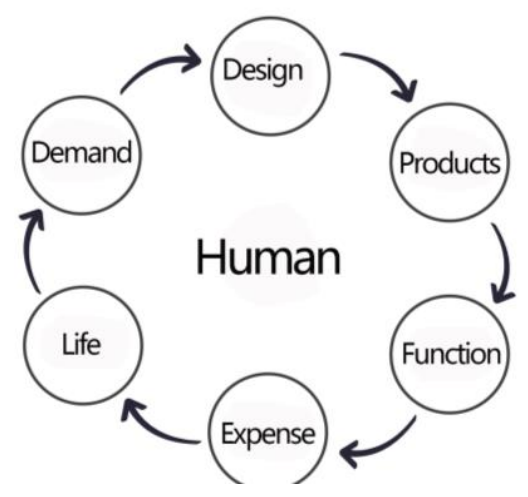

Fig. 3. Cyclic graph of the relation between function and human.

\section{FUNCTIONAL DESIGN AND FUTURE}

The design that the people made and aimed at the function of a product is the functional design, which is in fact the core of the design. The core of a design is inseparable from the combination of science, technology and art, and it is inseparable from human creativity. The famous scientist Mr. Li Zhengdao once said that "science and art are inseparable, like two sides of a coin. Their common foundation is human creativity. The goal they pursue is the universality of truth." Human creativity is enormous; thus, the functional design and the trends of future development are closely tied to human creativity. The function of a product changes with design capabilities. The author believes that in the future, the population on the Earth will continue to increase, and natural materials shortages, environmental pollution, and various conflicts will occur at any time. Therefore, designers are going to face with even greater challenges. Targeting at the functional design, numerous factors are required to be taken in consideration, including advanced technologies, low cost, greening and environmental conservation, humanization, emotionalizing, sustainable development, and other development trends of diversified design, of which the science and technicalization as well as the sustainable development are the two major trends in the future development of functional design.

\section{A. Science and Technicalization}

The science and technology are the primary productive forces, which drive the development and change of the entire human society. With the continuous advancement of science and technology, the mankind has used science and technology to be more extensive and trustworthy, designed and created for the needs of human life, satisfying human curiosity and conquering hearts. In the future, the highly advanced science and technology will provide technical support, material protection, and new artistic expressions for the design. There are three kinds of "concentric circles" model relationship between design, function and science and technology. The science and technology among them are a highly unified model of matter and spirit, the core and basis. And the designing is outspreading and creating objects on the basis of science and technology, and obtains a product with functions. These three are interconnected and complement with one another in "Fig. 4". With new materials and new technologies, new design products are constantly being produced. These new products have different practical functions. These new functions continue to meet and solve the various problems that humans are faced with in their development. The current artificial intelligence robot that leads the high-tech cutting-edge level is taken as an example. In 2016, the artificial intelligence robot AlphaGo of Google defeated the master of Go in the show against South Korea's master Li Shishi. The scientist Gareth thinks "the intelligence of artificial intelligence is trillions of trillions of times human beings (1024)" ${ }^{3}$ Assuming a basis of such high-speed, high-efficiency, automatic, and intelligent computing capabilities, and the robot will be given with selfawareness, creativity, emotion, aesthetics, and deceitful functions, it is that humans have created a new species, "Superman," and this phenomenon of "creation of God" has become increasingly clear. In 2017, the robot SOPHIA became the first robot to obtain a human citizenship identity card. In the Riyadh Future Investment Initiative Forum and the press conference, Sofia has shown self-awareness and appropriate independent emotional expression in conversations with reporters and hosts. At present, Google has established an ethics committee to handle and supervise related issues in the field of artificial intelligence. From the example of the Sofia artificial intelligence robot, we can find that the direction of design is a high-tech trend, and the functions of the products are more and more complete, intelligent, diversified, and humane in the future. The problems encountered in the design may be the handling of the stability and reliability of the various functions of the product. We can realize that the functions of designing products are diverse, sound, and high-tech, while the stability and reliability of the product features is still in need of improvement, from the breakdowns in the work of China's lunar probe "Yutu" rover and the US Mars Exploration Machine "Cursic" rover

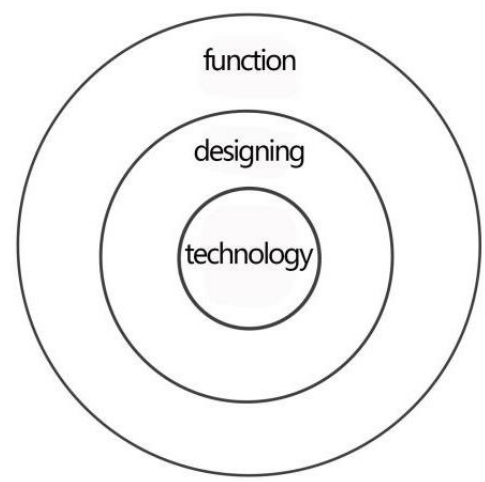

Fig. 4. The relation pattern among technology, designing, and function.

\footnotetext{
3 Hugo de Garis, Intelligence brief history- who will replace human beings and become the main species [M], Beijing: Tsinghua University Press, 2007:2.
} 


\section{B. Sustainable Development}

From the current trend of functional design, it can be observed that most of products cannot be decomposed and return to nature to cause environmental pollution after the end of the life of a product function. Correspondingly, people have proposed the concept of sustainable development of functional design. The "sustainable development" of functional design means that the product's practical function or material itself has the ability of secondary circulation or post-transformation, and after transformation, it changes the original functional properties into products with other functions, and it gains the sustainable capabilities and the ability to persist in time. The concept of sustainable development stems from the "Definition of Brundtland" proposed by the World Environment and Development Commission in 1987. The definition states that sustainable development not only meets the needs of the contemporary people, but also does not undermine the development of the ability of future generations to meet their needs. In this environment, the functional design concept slowly developed.

The sustainable development of functional design is a diversity of ideas, including a variety of multi-level views, and a wide range of terms. It is a highly generalized term. For example, the UNESCO's 10 key themes: poverty eradication, gender equality, health promotion, environmental protection, rural transformation, human rights, cross-cultural understanding and peace, sustainable production and consumption, cultural diversity and information and communications Technology and other projects can run through all functional design concepts. From the above 10 thematic projects alone, it can be concluded that the sustainable development of functional design is a complex and diversified concept, while a conclusion obtained after summing up is that the central idea is divided into three major sections: Earth, Human, and Design. The earth is the natural environment on which our human beings depend for survival. In order to survive, mankind obtains material resources from nature, and designs and labors to produce products with useful functions and serves itself to transform sustainable development of nature. The internal structure of the sustainable development of functional design is closely linked, and the internal structures are closely linked to each other. During the survival and development of human beings, the balance will be missed and he structure cannot sustain a development if one of the layers of structural defects occurs in "Fig. 5".

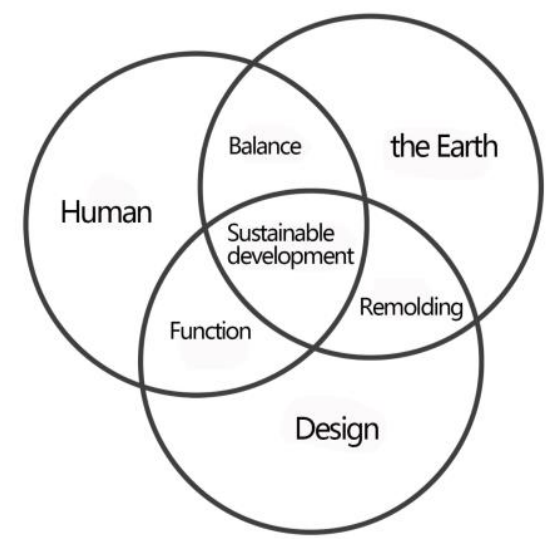

Fig. 5. Internal structure diagram of the sustainable development of the functional design.

In terms of human survival and development, the core of the functional design research is poverty alleviation and environmental protection. The poverty is not an evil in itself, but sustainable development requires the expansion from meeting the basic needs of people to the opportunity for everyone to enjoy a better life. Once the poverty is out of control, it will easily lead to global ecological and other disasters. ${ }^{4}$ For the people in poor areas, their survival is of primary importance, and ecological protection is secondary, and hence, the price and function of the product ought to be firstly considered in product design. For example, the "LifeStraw" high-performance portable water purifier invented by the Danish company "Vestergaard Flanders" has a low price, portability, and superior purification performance. The sewage is purified into drinking water. It can effectively remove bacteria and parasites that cause common diarrhoeal diseases and does not require electricity and spare facilities. It can be carried around to obtain safe and clean water. The design product, "LifeStraw," has solved many basic problems of life protection for the majority of poor people in environmental pollution areas. It seems to the author that a good design should have been designed for the masses of people as described in Barbara Blauchik's products designed for $90 \%$ of other people, "Instead of the appearance of the product, the emphasis is that it is limited in performance but cheap in price. With inherently revolutionary power, it can even save people's lives in some situations." Especially for people in poor areas, the price and function are the focus of the consumption. Poverty alleviation must be tied with environmentally friendly. If the poverty alleviation brings more problems to the future, it is not the best long-term plan to single-mindedly pursue economic development. Briefly speaking, we cannot prosper if the environment is objective to accommodate us. ${ }^{5}$ In short words, through analysis of the past, the present and the future, the functional design always plays the role of the core of a product design. The functional design has therefore

World Environment and Development Committee, Our common future [M] Wang Zhijia and Ke Jinliang translated, Jilin City: Jilin People's Press, 1987:27.

[UK] Anne • Cheek, Paul • Mikkelsveit. Sustainable design reform [M], Zhang Jun translated, Changsha: Hunan University Press, 2012:70 
demonstrated the development of diversification and sustainability in the design of the future. The functional design of its products is modeled after the design concept of "LifeStraw" and will play a role in environmental protection, low cost, technology, and humanity in the future. Chemical, functional and sustainable development capabilities.

\section{CONCLUSION}

Not only involved with art and science, designing is also the products crystalized by the comprehensive knowledge of human beings, as well as the products born by cultures. Designing is the function itself, and the function is a mirror of designing, reflecting the nature of designing. The relation itself between designing and function merges them into an undividable unity. These two shape a complex, intertwisted, and changeable connection with other disciplines, jointly propelling the history and future of the mankind. From the perspective of the development vein of design and function alone, both of the horizontal and vertical development is subject to the domination of humans, with which the diversity of collective development and mutual interactions of multiple disciplines has been formed in the demand and variations of human social life. In the future development of designing and function, the factors need of consideration by the designers are in an increase, including social services, lack of natural resources, environmental pollution, natural disasters, viruses, wars, extinction of species, life sciences, human destiny, human care and happiness, and so on; To the designer, these factors shape higher and more challenges for the designers. In the future, new disciplines and new knowledge points will constantly emerge in the human civilization, influencing and promoting the perfection and variation of designing and function.

\section{REFERENCES}

[1] Jiansu Province colleges and universities Marxist Philosophy wring group. Marxist philosophy [M], Nanjing: Jiangsu People's Publishing, Ltd, 1981.

[2] Li Yanzu, Introduction to art design [M], Wuhan: Hubei Fine Arts Press, 2009.

[3] Wang Shouzhi, World modern design history [M], Beijing: China Youth Publishing Group, 2002

[4] [US] Victor- Maglin, Design problem-history-theory-criticism [M], Liu Sha and Zhang Duoduo translated, Beijing: China Architecture\& Building Press, 2009.

[5] [UK] Alice-Rawsthorn, Design, for better world [M], Gong Yuan translated, Guilin: Guangxi Normal University Press, 2015. 